\title{
PERBANDINGAN POSISI KNEE JOINT FLEKSI DAN EXTENSI PEMERIKSAAN LUMBOSACRAL ANTERO POSTERIOR (AP) SUPINE DALAM MEMPERLIHATKAN DISCUS INTERVERTEBRALIS
}

\author{
Ceccare Noerma Kurniawan ${ }^{1)}$, Yeni Cahyati ${ }^{2}$, Rizki Agung Basuki ${ }^{3)}$ \\ ${ }^{1,2,3}$ Departement Of Radiodiagnostic and Radiotherapy, STIKes Widya Cipta Husada, Indonesia \\ Corresponding author: Written name of author (10 pt) \\ e-mail : ceccare97@gmail.com ${ }^{1)}$ yenic2638@gmail.com ${ }^{2)}$ RizkiagungbasukiRAD@gmail.com ${ }^{3)}$
}

\begin{abstract}
Background : Supine examination of lumbosacral antero posterior projection (AP) is used to obtain a clear lumbosacral radiograph, one of which shows an intervertebral disc. The objective the research was to determine the knee joint flexion position and knee joint extension position on the antero posterior lumbosacral (AP) Supine examination in the appearance of intervertebral discs.

Methods : Research of the position of the knee joint flexion and extension on the lumbosacral antero posterior (AP) Supine examination in displaying intervertebral discs, this is a comparative descriptive study, the researchers compared the position of the knee joint flexion and extension on Supine's lumbosacral antero posterior (AP) examination in showing the intervertebral disc so that it can be seen which position is better in performing Supine antero posterior (AP) lumbosacral radiographic examination in showing the intervertebral disc and which radiograph results. the best in establishing the diagnosis

Result : From the research data in showing the knee joint flexion and extension position, the mean value of the joint gap on Supine's lumbosacral (AP) examination in showing L-1 intervertebral disc in the knee joint flexion position was $8.8 \mathrm{~mm}$ while the knee joint extension position was $8.8 \mathrm{~mm} .7 \mathrm{~mm}$ intervertebral disc L-2, knee joint flexion is $10.2 \mathrm{~mm}$, while knee joint extension is $9.2 \mathrm{~mm}$, intervertebral disc L-3, knee joint flexion is $9 \mathrm{~mm}$, while knee joint extension is $7.8 \mathrm{~mm}$, intervertebral disc L-4 knee joint flexion position is $11 \mathrm{~mm}$ while knee joint extension is $9.8 \mathrm{~mm}$, lumbal sacrum joint knee joint flexion is $9 \mathrm{~mm}$ while knee joint extension is $6.6 \mathrm{~mm}$.

Conclusion : The position of the knee joint flexion on the lumbosacral antero posterior (AP) examination Supine is better at showing the anatomical structure of the vertebral bodies, intervertebral discs, intervertebral foramen L1-L4, spinous processes, sacrum, and intervertebral disc joint gaps, intervertebral disc. The position of the knee joint extension on the examination of the lumbosacral antero posterior (AP) Supine can reveal the anatomical structures of the vertebral bodies, intervertebral discs, intervertebral foramen L1-L4, spinous processes, sacrum, but in revealing intervertebral disc joints, Intervertebral disc.
\end{abstract}

Keywords : Lumbosacral, discus intervertebralis, flexion position, extension

\section{Pendahuluan}

Pemeriksaan radiografi merupakan salah satu pemeriksaan identifikasi struktur anatomi tubuh, karena pemeriksaan radiografi dapat memberikan gambaran dari struktur anatomis secara visual (Sparzinanda, 2017). Sejak ditemukannya sinar-X oleh Prof. Dr. Wilhelm Conrad Roentgen pada tanggal 8 November 1895, bidang radiologi mulai mengalami perkembangan baik di bidang radiodiagnostik maupun radioterapi.
Radiodiagnosik merupakan pemanfaatan sinar-X dalam mendiagnosis penyakit tanpa diperlukannya tindakan pembedahan untuk pasien (Prita et al, 2012). Salah satunya adalah teknik radiografi lumbosacral. Teknik radiografi Lumbosacral adalah suatu teknik radiografi yang bertujuan untuk menghasilkan gambaran tulang lumbal sampai sacrum. Umumnya pemeriksaan lumbosacral menggunakan proyeksi antero posterior dengan posisi antero posterior (AP) Supine. Salah satu penerapan pemeriksaan 
lumbosacral menggunakan proyeksi antero posterior (AP) Supine adalah pada kasus Low Back Pain (LBP). Low Back Pain (LBP) merupakan suatu penyakit yang gejala utamanya adalah terasa nyeri atau pegal pada punggung bagian bawah. Nyeri punggung bawah menyebabkan penderita mengalami suatu kekurangmampuan yaitu keterbatasan fungsional dalam aktifitas sehari-hari Rahim et al, (2012).

Pada pemeriksaan lumbosacral antero posterior (AP) Supine terdapat berbagai macam posisi yaitu posisi knee joint fleksi dan posisi knee joint extensi. Menurut Bontrager (2014), posisi knee joint fleksi dengan menekuk lutut menjadikan tulang lumbosacral lebih dekat dan sejajar dengan meja pemeriksaan serta posisi knee joint fleksi memungkinkan kenyamanan pasien lebih besar sedangkan posisi knee joint extensi dengan meluruskan kaki sehingga lutut juga lurus.

Secara teori, pemeriksaaan lumbosacral proyeksi antero posterior (AP) Supine menggunakan posisi knee joint fleksi dan pasien harus menggunakan alat fiksasi, tetapi pada saat di instalasi RSUD X, proyeksi pemeriksaaan lumbosacral proyeksi AP Supine menggunakan posisi knee joint extensi tanpa alat fiksasi (Bontrager, 2014). Pemeriksaan lumbosacral proyeksi antero posterior (AP) Supine dimanfaatkan untuk mendapatkan hasil gambaran radiograf lumbosacral dengan jelas salah satunya menampakan discus intervertebralis. Discus intervertebralis merupakan bantalan tebal dari tulang rawan fibrosa yang terdapat diantara badan vertebrae yang dapat bergerak (Pearce, 2009). Tujuan penelitian ini adalah untuk mengetahui posisi knee joint fleksi dan untuk mengetahui posisi knee joint extensi pada pemeriksaan lumbosacral antero posterior (AP) Supine dalam menampakan discus intervertebralis.

\section{Metode}

Pada penelitian perbandingan posisi knee joint fleksi dan extensi pada pemeriksaan lumbosacral antero posterior $(A P)$ Supine dalam menampakan discus intervertebralis merupakan penelitian deskriptif komparatif.

Dalam penelitian ini peneliti membandingkan posisi knee joint fleksi dan extensi pada pemeriksaan lumbosacral antero posterior $(A P)$
Supine dalam menampakan discus intervertebralis sehingga dapat diketahui posisi yang lebih baik dalam melakukan pemeriksaan radiografi lumbosacral antero posterior (AP) Supine dalam menampakan discus intervertebralis dan hasil radiograf manakah yang paling baik dalam menegakkan diagnosa, penelitian menggunakan sampel sebanyak 5 orang. Sampel yang diteliti yaitu pasien dengan permintaan pemeriksaan lumbosacral antero posterior (AP) dan lateral. Sampel diexpose dua kali dengan dua perlakuan yang berbeda oleh peneliti. Dari perbedaan kedua posisi knee joint fleksi dan extensi dan hasil radiograf maka dibandingkan dengan memberi wawancara dan checklist kepada 3 orang dokter radiologi dan wawancara 5 radiografer. Data yang didapat kemudian diolah, dibahas dan diambil kesimpulan.

Tempat dan Waktu Penelitian: Tempat pengambilan data dalam penelitian ini adalah di Instalasi Radiologi RSUD Mojosari. Peneliti melakukan penelitian di Instalasi Radiologi RSUD Mojosari dimulai dari bulan April 2019 sampai bulan Mei 2019.

Populasi dan Sampel: Populasi dalam penelitian ini yaitu pasien yang datang ke instalasi radiologi RSUD Mojosari dengan membawa surat permintaan foto pemeriksaan lumbosacral antero posterior (AP) dan Lateral selama satu bulan dengan populasi 10 orang. Dalam pengambilan sampel yang digunakan dalam penelitian ini menggunakan metode nonprobabilitas dengan teknik purposive sampling (Sugiyono, 2009). Menurut Nasution, (2003). Pengambilan sampel dari 10 populasi menjadi 5 sampel, sebagai berikut:

$$
\mathrm{K}=\frac{\mathrm{N}}{2}
$$

Keterangan :

$\mathrm{K}=($ Hasil sampel $), \mathrm{N}=($ Jumlah anggota populasi)

a. Kriteria inklusi dalam penelitian ini adalah pasien dengan pemeriksaan lumbosacral antero posterior $(A P)$ dan Lateral, pasien dapat berdiri (kooperatif), pasien dengan kasus Low Back Pain $(L B P)$, pasien dewasa dengan usia diatas 25 tahun sampai dengan masa manula (65 - 
sampai keatas) (Depkes RI. 2009) dan pasien bersedia menjadi sampel.

b. Kriteria eksklusi penelitian ini yaitu pasien yang keadaannya emergency dan pasien yang tidak bersedia menjadi sampel penelitian ini.

Variabel Penelitian: Variabel bebas pada penelitian ini adalah posisi knee joint fleksi pada pemeriksaan radiografi lumbosacral antero posterior (AP) Supine dan posisi knee joint extensi pada pemeriksaan radiografi lumbosacral antero posterior (AP) Supine. Sedangkan variabel terikat dalam penelitian ini adalah hasil radiograf dalam menampakan discus intervertebralis.

Teknik Pengumpulan Data : Untuk mendapatkan data yang lengkap dan maksimal maka dalam penelitian ini, menggunakan beberapa cara untuk mengumpulkan data, seperti observasi, checklist, wawancara, dan dokumentasi.

Pasien datang ke instalasi radiologi dengan membawa surat permintaan melakukan pemeriksaan radiografi lumbosacral, kemudian peneliti meminta ijin kepada pasien untuk dijadikan sampel, apabila pasien menyetujui, peneliti memberikan penjelasan pemeriksaan dan mencocokan data pasien dengan pasien dengan klinis low back pain di Instalasi Radiologi RSUD Mojosari. Sampel diexpose dua kali dengan dua perlakuan yang berbeda dengan posisi knee joint fleksi dan posisi knee joint extensi dalam menampakan discus intervertebralis yang dilakukan oleh peneliti yang dilihat oleh radiografer dan dokter spesialis radiologi di Instalasi Radiologi RSUD Mojosari. Pada penelitian ini, terlebih dahulu peneliti mengumpulkan surat permintaan foto pemeriksaan lumbosacral antero posterior (AP) dan lateral.

Peneliti akan memberikan form checklist kepada responden adalah 3 dokter spesialis radiologi dengan simbol berupa R1, R2, dan R3 . Dokter spesialis radiologi mengisi lembar checklist anatomi memberi tanda centang salah satu antara posisi knee joint fleksi dan posisi knee joint extensi yang lebih baik dalam menampakan corpus vertebralis, discus intervertebralis, discus intervertebralis lumbal-1, discus intervertebralis lumbal-2, discus intervertebralis lumbal-3, discus intervertebralis lumbal-4, lumbal sacrum joint, foramen intervertebralis L1-LA, prosesus spinous, dan sacrum dan terbukanya sendi discus intervertebralis.

Peneliti melakukan wawancara terhadap 3 dokter radiologi dengan simbol berupa R1, R2, dan R3 tentang kualitas hasil radiograf discus intervertebralis pada pemeriksaan lumbosacral antero posterior (AP) Supine lebih baik menggunakan posisi knee joint fleksi atau posisi knee joint extensi dan 5 radiografer dengan simbol berupa $\mathrm{C} 1, \mathrm{C} 2, \mathrm{C} 3, \mathrm{C} 4$ dan $\mathrm{C} 5$ tentang pemeriksaan lumbosacral antero posterior $(A P)$ Supine lebih baik menggunakan posisi knee joint fleksi atau posisi knee joint extensi.

Pada penelitian ini, peneliti mendokumentasikan, meliputi alat, hasil radiograf, hasil checklist kepada 3 dokter spesialis radiologi, dan hasil wawancara kepada 3 dokter spesialis radiologi dan 5 radiografer.

Analisis Data: Berdasarkan hasil checklist kepada dokter spesialis radiologi dan wawancara kepada 3 dokter spesialis radiologi dan 5 radiografer sesuai dengan parameter dalam menampakan corpus vertebralis, discus intervertebralis, foramen intervertebralis L1-LA, prosesus spinous, lumbal sacrum joint, sacrum, dan terbukanya sendi discus intervertebralis. Data yang didapat kemudian diolah, dibahas dan diambil kesimpulan.

\section{Hasil dan Pembahasan}

\section{Karakteristik Sampel Berdasarkan Umur}

Tabel 1. Karakteristik sampel berdasarkan umur

\begin{tabular}{|l|l|l|}
\hline No. & Sampel & Umur \\
\hline 1. & Tn. U & 60 Tahun \\
\hline 2. & Tn. K & 77 Tahun \\
\hline 3. & Tn. M & 50 Tahun \\
\hline 4. & Tn. MK & 46 Tahun \\
\hline 5. & Ny. D & 40 Tahun \\
\hline
\end{tabular}

Pemeriksaan lumbosacral dipengaruhi oleh usia, pada perempuan dan laki-laki, pada penelitian ini terjadi pada umur 40-77 tahun. Low back pain $(L B P)$ juga dapat terjadi pada lansia, umumnya discus intervertebralis akan mengalami perubahan sifat ketika usia bertambah tua (Nurlis et al, 2012). 


\section{Data Hasil Penelitian Dalam Menampakan Discus Intervertebralis Pada Pemeriksaan Lumbosacral Antero Posterior (AP) Supine Posisi Knee Joint Extensi dan Fleksi}

Tabel 2. Hasil Dalam Menampakan Discus Intervertebralis Pada Pemeriksaan Lumbosacral Antero Posterior (AP) Supine Posisi Knee Joint Extensi dan Fleksi.

\begin{tabular}{|l|l|c|c|}
\hline No. & \multicolumn{1}{|c|}{ Anatomi } & $\begin{array}{c}\text { AP Supine Posisi } \\
\text { Knee Joint Fleksi }\end{array}$ & $\begin{array}{c}\text { AP Supine Posisi } \\
\text { Knee Joint Extensi }\end{array}$ \\
\hline 1. & Corpus vertebralis & 14 & 1 \\
\hline 2. & Discus Interverterbralis & 15 & 0 \\
\hline & a. Discus Interverterbralis L 1 & 15 & 0 \\
& b. Discus IIterverterbralis L 2 & 15 & 0 \\
& c. Discus Interverterbralis L 3 & 15 & 0 \\
& d. Discus Interverterbralis L 4 & 15 & 0 \\
\hline 3. & Lumbal sacrum joint & 15 & 0 \\
\hline 4. & Foramen intervertebralis L1-L4 & 15 & 0 \\
\hline 5. & Prosesus spinous & 14 & 1 \\
\hline 6. & Sacrum & 10 & 5 \\
\hline 7. & Terbukanya sendi Discus & 15 & 0 \\
\hline
\end{tabular}

Berdasarkan Tabel 2 pada pemeriksaan Lumbosacral (AP) Supine lebih baik menggunakan posisi knee joint fleksi karena dapat menampakan struktur anatomi corpus vertebralis, discus intervertebralis, discus intervertebralis Lumbal-1, discus intervertebralis Lumbal-2, discus intervertebralis Lumbal-3, discus intervertebralis Lumbal-4, lumbal sacrum joint, foramen intervertebralis Lumbal 1-Lumbal 4, prosesus spinous, sacrum dan terbukanya sendi discus intervertebralis dilihat dari data checklist oleh dokter spesialis radiologi. Dan pada Tabel 2 sesuai dengan gambaran hasil radiograf pada penelitian. Adapun hasil radiograf lumbosacral posisi fleksi dan extensi dapat dilihat seperti pada Gambar 1 dan Gambar 2.

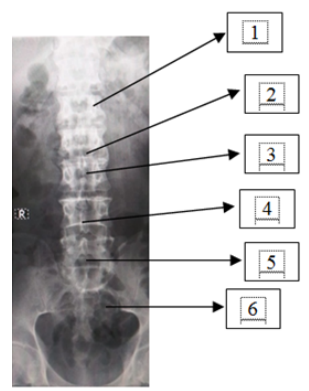

\section{Keterangan Gambar :}

1. Corpus vertebralis

2. Discus Intervertebralis

3. Foramen intervertebralis

4. Prosesus spinous

5. Lumbal sacrum joint

6. Sacrum

Gambar 1. Hasil Radiograf Lumbosacral posisi fleksi

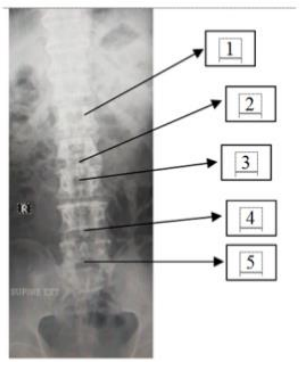

Keterangan Gambar :

1. Corpus vertebralis

2.Discus Intervertebralis

3.Foramen intervertebralis

4.Prosesus spinous

5.Lumbal sacrum joint

6.Sacrum

Gambar 2. Hasil Radiograf Lumbosacral posisi extensi

Dari Gambar 1 dan Gambar 2 hasil radiograf lumbosacral antero posterior (AP) Supine dalam menampakan struktur anatomi corpus vertebralis, discus intervertebralis, foramen intervertebralis, prosesus spinous, lumbal sacrum joint, sacrum dan terbukanya sendi discus intervertebralis lebih baik menggunakan posisi knee joint fleksi. Dari hasil checklist dan wawancara R1,R2, dan R3, kelebihan menggunakan posisi knee joint fleksi adalah lebih bagus pada penampakan lumbar intervertebralis dan prosesus spinosus serta dengan posisi knee joint fleksi, discus intervertebralis lebih terbuka. Sedangkan kekurangan menggunakan posisi knee joint fleksi, menurut radiolog R1,R2, dan R3 tidak ada kekurangan, tetapi dari hasil wawancara peneliti dengan radiografer $\mathrm{C} 1, \mathrm{C} 2, \mathrm{C} 3, \mathrm{C} 4$ dan $\mathrm{C} 5$, kekurangan menggunakan posisi knee joint fleksi yaitu adanya pergerakan pasien pada saat diposisikan.

Dari hasil checklist dan wawancara R1,R2, dan R3, pada Gambar 1 dan Gambar 2 kelebihan menggunakan posisi knee joint extensi adalah bisa menampakan struktur anatomi corpus vertebralis, discus intervertebralis, foramen intervertebralis, prosesus spinous, lumbal sacrum joint, sacrum. Sedangkan kekurangan menggunakan posisi knee joint extensi adalah posisi knee joint extensi kurang terbuka dalam menampakan discus intervertebralis.

Data Hasil Penelitian dalam Menampakan Celah Sendi Posisi Knee Joint Fleksi dan Extensi 
Tabel 3. Hasil Penelitian dalam Menampakan Celah Sendi Posisi Knee Joint Fleksi dan Extensi

\begin{tabular}{|c|c|c|}
\hline \multirow{2}{*}{ Anatomi } & \multicolumn{2}{|c|}{$\begin{array}{c}\text { Nilai Rata-rata celah sendi pada pemeriksaan } \\
\text { Lumbosacral }\end{array}$} \\
\cline { 2 - 3 } & $\begin{array}{c}\text { AP Supine Posisi Knee } \\
\text { Joint Fleksi }(\mathrm{mm})\end{array}$ & $\begin{array}{c}\text { AP Supine Posisi Knee } \\
\text { Joint Extensi }(\mathrm{mm})\end{array}$ \\
\hline Discus Intervertebralis L-1 & 8,8 & 7 \\
\hline Discus Intervertebralis L-2 & 10,2 & 9,2 \\
\hline Discus Intervertebralis L-3 & 9 & 7,8 \\
\hline Discus Intervertebralis L-4 & 11 & 9,8 \\
\hline Lumbal sacrum joint & 9 & 6,6 \\
\hline
\end{tabular}

Berdasarkan Tabel 3 nilai rata-rata celah sendi pada pemeriksaan Lumbosacral (AP) Supine dalam menampakan Discus Intervertebralis Lumbal-1 lebih baik dengan posisi knee joint fleksi sebesar 8,8 mm, Discus Intervertebralis Lumbal2 lebih baik dengan posisi knee joint fleksi sebesar 10,2 mm, Discus Intervertebralis Lumbal-3 lebih baik dengan posisi knee joint fleksi sebesar $9 \mathrm{~mm}$, Discus Intervertebralis Lumbal-4 lebih baik dengan posisi knee joint fleksi sebesar $11 \mathrm{~mm}$, Lumbal sacrum joint lebih baik dengan posisi knee joint fleksi sebesar $9 \mathrm{~mm}$. Dan pada Tabel 3 sesuai dengan gambaran hasil radiograf pada penelitian. Adapun hasil radiograf discus intervertebralis dan lumbal sacrum joint posisi fleksi dapat dilihat seperti pada Gambar 3 dan Gambar 4.

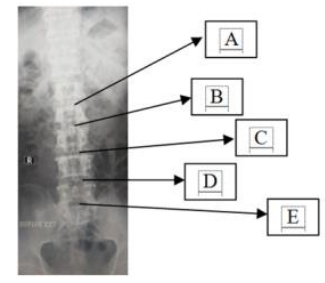

Keterangan Gambar :

A. Discus Intervertebralis L-1

B. Discul Intervertebralis $L-2$

C. Discus Intervertebralis L-3

D. Discus Intervertebralis $L-4$

E. Lumbal sacrum joint

Gambar 3. Discus Intervertebralis dan Lumbal sacrum joint posisi fleksi

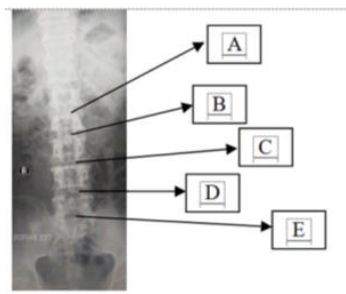

\section{Keterangan Gambar}

A. Discus Intervertebralis $L-1$

B. Discus Intervertebralis L-2

C. Discus Intervertebralis $L-3$

D. Discus Intervertebralis $L-4$

E. Lumbal sacrum joint

Gambar 4. Discus Intervertebralis dan Lumbal sacrum joint posisi extensi

Dari Gambar 3 dan Gambar 4 hasil radiograf discus intervertebralis dan lumbal sacrum joint dalam menampakan struktur anatomi discus intervertebralis Lumbal-1, discus intervertebralis Lumbal-2, discus intervertebralis Lumbal-3, discus intervertebralis Lumbal-4, lumbal sacrum joint lebih baik menggunakan posisi knee joint fleksi. Dari hasil checklist dan wawancara R1, R2, dan R3, kelebihan menggunakan posisi knee joint fleksi adalah lebih bagus pada penampakan lumbar intervertebralis dan prosesus spinosus serta dengan posisi knee joint fleksi, discus intervertebralis lebih terbuka. Sedangkan kekurangan menggunakan posisi knee joint fleksi adalah kedua posisi fleksi dan extensi dapat menampakan discus intervertebralis.

Dari hasil checklist dan wawancara R1, R2, dan R3, kelebihan menggunakan posisi knee joint extensi adalah bisa menampakan struktur anatomi discus intervertebralis $L-1$, discus intervertebralis $L-2$, discus intervertebralis $L-3, \quad$ discus intervertebralis L-4, lumbal sacrum joint. Sedangkan kekurangan menggunakan posisi knee joint extensi adalah kurang terbuka dalam menampakan discus intervertebralis.

Pembahasan

Pemeriksaan lumbosacral antero posterior $(A P)$ Supine dapat dilakukan dengan dua perlakuan yang berbeda, yaitu dengan posisi knee joint fleksi dan extensi. Pemeriksaan lumbosacral antero posterior (AP) Supine pada penelitian ini bertujuan untuk mengetahui posisi knee joint fleksi dan posisi knee joint extensi pada pemeriksaan lumbosacral antero posterior (AP) Supine dalam menampakan discus intervertebralis. Berdasarkan hasil wawancara, kedua posisi fleksi dan extensi dapat menampakan discus intervertebralis, tetapi posisi knee joint extensi kurang terbuka dalam menampakan discus intervertebralis.

Dari data hasil penelitian dalam menampakan celah sendi posisi knee joint fleksi dan extensi, nilai rata-rata celah sendi pada pemeriksaan lumbosacral (AP) Supine dalam menampakan Discus Intervertebralis L-1 posisi knee joint fleksi sebesar $8,8 \mathrm{~mm}$ sedangkan posisi knee joint extensi sebesar $7 \mathrm{~mm}$, Discus Intervertebralis L-2 posisi knee joint fleksi sebesar 10,2 mm sedangkan posisi knee joint extensi sebesar 9,2 mm, Discus Intervertebralis $L-3$ posisi knee joint fleksi sebesar $9 \mathrm{~mm}$ sedangkan posisi knee joint extensi sebesar 7,8 mm, Discus Intervertebralis L-4 posisi knee joint fleksi sebesar $11 \mathrm{~mm}$ sedangkan posisi knee 
joint extensi sebesar 9,8 mm, Lumbal sacrum joint posisi knee joint fleksi sebesar $9 \mathrm{~mm}$ sedangkan posisi knee joint extensi sebesar 6,6 $\mathrm{mm}$. Sehingga hasil penelitian sesuai dengan teori, dimana lebar celah sendi antar discus intervertebralis sebesar 8 $\mathrm{mm}$ (Suyasa et al, 2018).

Dari data hasil dalam menampakan discus intervertebralis pada pemeriksaan lumbosacral antero posterior (AP) Supine lebih baik menggunakan posisi knee joint fleksi karena dapat menampakan struktur anatomi corpus vertebralis, discus intervertebralis, discus intervertebralis Lumbal-1, discus intervertebralis Lumbal-2, discus intervertebralis Lumbal-3, discus intervertebralis Lumbal-4, lumbal sacrum joint, foramen intervertebralis Lumbal 1-Lumbal 4, prosesus spinous, sacrum dan terbukanya sendi discus intervertebralis dilihat dari data checklist oleh dokter spesialis radiologi.

Berdasarkan wawancara peneliti dengan radiolog R1, R2 dan R3, didapatkan bahwa kedua posisi knee joint fleksi atau posisi knee joint extensi dapat menampakan discus intervertebralis, tetapi menggunakan posisi knee joint fleksi lebih baik dalam menampakan struktur anatomi lumbar intervertebralis dan prosesus spinous serta discus intervertebralis lebih terbuka.

Berdasarkan wawancara peneliti dengan radiografer $\mathrm{C} 1, \mathrm{C} 2, \mathrm{C} 3, \mathrm{C} 4$ dan $\mathrm{C} 5$ didapatkan bahwa tidak ada perlakuan khusus pada pemeriksaan lumbosacral (AP) Supine dengan posisi knee joint fleksi dan posisi knee joint extensi. Pada pemeriksaan lumbosacral (AP) Supine lebih baik menggunakan posisi knee joint fleksi karena lumbosacral lebih menempel pada meja pemeriksaan dan discus intervertebralis lebih terbuka serta pasien lebih nyaman.

\section{Simpulan}

Kesimpulan pada penelitian ini adalah posisi knee joint fleksi pada pemeriksaan lumbosacral antero posterior (AP) Supine lebih baik dalam menampakan struktur anatomi corpus vertebralis, discus intervertebralis, foramen intervertebralis L1-LA, prosesus spinous, sacrum, dan celah sendi discus intervertebralis, Discus Intervertebralis L1, Discus Intervertebralis L-2, Discus Intervertebralis L-3, Discus Intervertebralis L-4, Lumbal sacrum joint lebih terbuka. Posisi knee joint extensi pada pemeriksaan lumbosacral antero posterior (AP) Supine bisa menampakan struktur anatomi corpus vertebralis, discus intervertebralis, foramen intervertebralis L1-LA, prosesus spinous, sacrum, tetapi dalam menampakan celah sendi discus intervertebralis, Discus Intervertebralis L-1, Discus Intervertebralis L-2, Discus Intervertebralis L-3, Discus Intervertebralis L-4, Lumbal sacrum joint lebih baik menggunakan posisi knee joint fleksi karena pada extensi kurang terbuka.

Saran pada penelitian ini adalah pemeriksaan lumbosacral antero posterior (AP) Supine sebaiknya menggunakan posisi knee joint fleksi dalam menampakan discus intervertebralis, Discus Intervertebralis L-1, Discus Intervertebralis L-2, Discus Intervertebralis L-3, Discus Intervertebralis L-4, Lumbal sacrum joint karena lumbosacral lebih menempel pada meja pemeriksaan dan discus intervertebralis lebih terbuka serta pasien lebih nyaman. Untuk penelitian selanjutnya, sebaiknya ada standart fleksi (penyudutan) dan alat imobilisasi serta ada standart operasional prosedur (SOP) yang digunakan untuk pemeriksaan lumbosacral antero posterior (AP) Supine dalam menampakan discus intervertebralis.

\section{Daftar Pustaka}

Bontrager, Kenneth L. 2014, Textbook of Radiographic Positioning and Related anatomy. Eighth Edition. St. Louis, Amerika: Mosby Inc.

Depkes RI. 2009. Profil Kesehatan Indonesia 2009. Jakarta: Kementerian Kesehatan Republik Indonesia.

Nasution, R. 2003. Teknik Sampling. Sumatera Utara: USU digital library.

Nurlis et al, 2012. Pengaruh Terapi Dingin Ice Massage Terhadap Perubahan IntensitasNyeri Pada Penderita Low Back Pain. Jurnal Ners Indonesia, Vol. 2, No. 2. Ejournal.unri.ac.id/index.php/JNI.

Pearce, Evelyn C., 2009.Anatomi dan Fisiologi Untuk Paramedis. Jakarta:PT Gramedia Pustaka Utama.

Prita, Fitria Sari, 2012.Analisis Nilai Ambang Energi Listrik Sinar-X pada Pemeriksaan Thorax Posterior Anterior (PA) Pasien di Instansi 
Radiodiagnostik RSUD Dr Soetomo Surabaya: Jember.

Rahim, Agus Hadian. 2012. Vertebrae. Jakarta: Departemen Ortopedi dan Traumatologi Fakultas Kedokteran Universitas Padjadjaran Rumah Sakit dr. Hasan Sadikin.

Sparzinanda, Eif. 2017. Pengaruh Faktor Eksposi Terhadap Kualitas Citra Radiografi: Mendalo Darat.
Sugiyono, Dr. Prof., 2009, Metode Penelitian Kuantitatif Kualitatif dan $R \& D$. Bandung: Alfabeta

Suyasa, I Ketut. 2018. Penyakit Degenerasi Lumbal Diagnosisdan Tata Laksana. Bali: Udayana University Press. 